\title{
Noise sensitivity: Symptoms, health status, illness behavior and co- occurring environmental sensitivities
}

\author{
Christos Baliatsas ${ }^{a^{*}}$, Irene van Kamp ${ }^{\text {b }}$, Wim Swart ${ }^{b}$, Mariëtte Hooiveld ${ }^{\text {a }}$, Joris Yzermans ${ }^{\text {a }}$ \\ ${ }^{a}$ Netherlands Institute for Health Services Research (NIVEL), Utrecht, The Netherlands \\ ${ }^{\mathrm{b}}$ National Institute for Public Health and the Environment (RIVM), Bilthoven, The Netherlands
}


Epidemiological evidence on the symptomatic profile, health status and illness behavior of people with subjective sensitivity to noise is still scarce. Also, it is unknown to what extent noise sensitivity cooccurs with other environmental sensitivities such as multi-chemical sensitivity and sensitivity to electromagnetic fields (EMF). A cross-sectional study performed in the Netherlands, combining selfadministered questionnaires and electronic medical records of non-specific symptoms (NSS) registered by general practitioners (GP) allowed us to explore this further. The study sample consisted of 5806 participants, drawn from 21 general practices. Among participants, 722 (12.5\%) responded "absolutely agree" to the statement "I am sensitive to noise", comprising the high noise-sensitive (HNS) group. Compared to the rest of the sample, people in the HNS group reported significantly higher scores on number and duration of self-reported NSS, increased psychological distress, decreased sleep quality and general health, more negative symptom perceptions and higher prevalence of healthcare contacts, GP-registered NSS and prescriptions for antidepressants and benzodiazepines. These results remained robust after adjustment for demographic, residential and lifestyle characteristics, objectively measured nocturnal noise exposure from road-traffic and GP-registered morbidity. Co-occurrence rates with other environmental sensitivities varied between $9 \%$ and $50 \%$. Individuals with self-declared sensitivity to noise are characterized by high prevalence of multiple NSS, poorer health status and increased illness behavior independently of noise exposure levels. Findings support the notion that different types of environmental sensitivities partly overlap.

Keywords: Noise sensitivity, Non-specific symptoms, Idiopathic environmental intolerance, Primary care 

to noise in general (Job, 1999) through pathways related to physiological, psychological, including attitudinal characteristics or pathways related to life style or activity patterns. There are a number of competing and complementary hypotheses regarding the etiology of noise sensitivity and its potential role (van Kamp et al., 2013): It could be a result of physical illness, injury, psychological disorder, a partial indicator of genetically related vulnerability or acquired vulnerability to environmental stressors, or even a side-effect of prescribed medication (van Kamp and Davies, 2013). Noise sensitivity might directly influence health or moderate the relationship between noise and well-being (Stansfeld 1992; Heinonen-Guzejev et al., 2007; Fyhri et al., 2009; Kishikawa et al., 2009). It has been linked to poor perceived health and increased psychological distress, morbidity, medication use and risk of disability pension (Stansfeld et al., 1993; Heinonen-Guzejev et al., 2004, 2013; Stansfeld and Shipley, 2015). There is also the notion that noise sensitivity could be part of the broader spectrum of subjective environmental sensitivities attributed to low, compared to the established safety limits, exposure levels to environmental agents such as chemicals and electromagnetic fields (EMF) (Nordin et al., 2013, Palmquist et al., 2014).

People with these environmental sensitivities are often characterized by increased report of non-specific symptoms (NSS) (Das-Munshi et al., 2006; Staudenmayer et al., 2003). Such symptoms occur in various organ systems and can be caused by multiple factors, often unknown and unrelated to the attributed (environmental) cause. When presented in primary care, between $30 \%$ and $50 \%$ of NSS cannot be explained by a medical diagnosis (Kroenke and Price 1993; Barsky and Borus, 1999). The term "medically unexplained" is often used to describe such complaints in clinical practice (Henningsen et al., 2011). Decreased physical functioning, increased illness behavior (particularly related to alternative therapies) and negative symptom perceptions have also been observed in some environmentally sensitive groups (Baliatsas et al., 2014).

However, it is not clear yet whether these features are also common in people with noise sensitivity. Noise-sensitive groups have been understudied, are generally underrepresented in study populations and evidence on differential characteristics is scarce (van Kamp and Davies, 2013), since there is limited research on their symptomatic profile, psychological relevant characteristics and cooccurrence with other environmental sensitivities. The present study addresses three main questions: 1) Do people with self-reported noise sensitivity experience more symptoms and symptoms of longer duration compared to the broader population? 2) Do noise-sensitive individuals differ from the broader population in terms of symptom report, symptom perceptions, health status indicators and illness behavior? 3) To what extent do noise- sensitive people report other environmental sensitivities as well? 


\section{Materials and methods}

\subsection{Participants and procedure}

Two data collection methods were combined in a population study conducted in 2011 in the Netherlands, originally designed to assess the association between EMF and NSS (Baliatsas et al., 2015): A questionnaire survey entitled "Living environment, technology and health" and electronic medical records (EMR) of adult citizens registered in 21 general practices. It is obligatory for every citizen in the Netherlands to be registered at a general practice; the population listed in family practice can be used as the denominator in epidemiological studies. (van der Lei et al., 1993). Practices in different regions were selected from the primary care database of the Netherlands Institute for Health Services Research (NIVEL). The final number of respondents were $n=5933$ (response rate: $46 \%$ ). The privacy regulation of the study was approved by the Dutch Data Protection Authority. According to the Dutch Medical Research Involving Human Subjects Act, ethical approval was not required for this study. More details on the study population and sampling process are described in earlier publications (Baliatsas et al., 2014, 2015).

\subsection{Case definition for noise sensitivity}

A single item on noise sensitivity was used, formatted on a five-point scale, which was part of a list assessing sensitivity to diverse environmental stressors, adapted from Stansfeld et al. (1985). Participants who reported "strongly agree" on the statement: "I am sensitive to noise", formed the high noise sensitivity (HNS) group. The rest of the sample was considered as the low(er)-sensitive (control) group (LNS).

\subsection{Case definitions for other environmental sensitivities}

Similar to the case definition for HNS, respondents who answered "strongly agree" to questions regarding other environmental stressors such as chemical substances, materials, smells in general, light, colors, scented detergents, warm/cold environment, temperature changes were defined as being highly environmentally sensitive. The case definition of electromagnetic (hyper)sensitivity/idiopathic environmental intolerance attributed to EMF (IEI-EMF) was based on the approach of Baliatsas et al (2014) ( "quite agree" or "strongly agree" on the statements: "I am sensitive to mobile phone base stations and devices related to communication systems" and "I am sensitive to electrical devices").

\subsection{Self-reported NSS and associated perceptions}

To assess NSS in terms of prevalence/number and duration, the corresponding subscales of the Symptoms and Perceptions (SaP) questionnaire (Yzermans et al., 2016) were used. The SaP questionnaire combines the assessment of 28 symptoms with an adapted version of the brief Illness Perception Questionnaire (B-IPQ) (Broadbent et al., 2006). A higher sum score on the symptom items indicates increased report and longer duration of NSS. The $28^{\text {th }}$ item ("Hypersensitivity to light or 
noise") was omitted due to overlap with the case-definition for the HNS group. The B-IPQ items refer to the symptom that was perceived as the most severe/important by the respondents, with a higher score reflecting more negative perceptions/beliefs.

\subsection{GP-registered NSS and prescribed medication}

Non-specific physical symptoms in EMR were registered by the general practitioners based on the international classification of primary care (ICPC) (Lamberts and Wood, 1987). The evaluation of the clinical judgment of the practitioner on the symptoms was based on "episodes of care" (WONCA, 1995). An episode was defined as "non-specific"/unexplained if there was no registered diagnosis for the symptoms, during the year before the completion of the study. Registered NSS corresponded to the symptom items of the self-reported list; when applicable, similar symptoms in the EMR were clustered (e.g headache and tension headache).

The prevalence of GP-registered prescriptions related to painkillers, benzodiazepines and antidepressants was also examined, using the Anatomical Therapeutic Chemical Classification system (ATC) (WHO, 2003).

\subsection{Health status indicators}

General health was assessed with the corresponding subscale of the RAND-36 Health Survey questionnaire (van der Zee and Sanderman, 1993). A higher score indicates better perceived health. Moreover, participants completed a 10-item version of the Sleep Quality Scale (Visser et al., 1978) and the 12-item version of the General Health Questionnaire (GHQ-12), using the 4-point Likert-type scoring method (Goldberg, 1973; Hoeymans et al., 2004). Higher total scores on these two scales indicate increased levels of sleep problems and psychological distress respectively.

\subsection{Indicators of illness behavior}

Participants reported whether they contacted a general practitioner and/or a psychologist or psychotherapist and/or an alternative therapist (e.g. homeopathist, acupuncturist or paranormal therapist) and also whether they used medication that did not require a medical prescription within the past year.

\subsection{Noise exposure and other covariates}

For each address, total night-time exposure to road traffic was estimated by means of the Standard Model Instrumentation for Noise Assessments (STAMINA) (Schreurs et al., 2010, 2011) and expressed in $\mathrm{L}_{\text {night, }}$, which is an unweighted indicator for an eight-hour night period. The STAMINA model was developed at the National Institute for Public Health and the Environment (RIVM), and is an instrument to map environmental noise in the Netherlands. It uses the standard Dutch Calculation method for traffic and industrial noise, which is used in the Netherlands to implement the European 
Environmental Noise Directive (European Commission. 2002). The calculations were done using based on detailed noise maps for the year 2011. The spatial resolution of the noise maps depends on the distance between source and observation point. The lowest resolution is $80 \times 80 \mathrm{~m}$, and close to the source, the level of detail is the highest, with a resolution of $10 \times 10 \mathrm{~m}$. The noise maps were used to assess the noise exposure for the place of residence of the participants for their highest exposed façade.

In the present study, night-time road-traffic noise was considered as a more relevant covariate compared to noise at daytime, due to its potential relation to symptoms such as fatigue and sleep problems which are among the prominent symptoms in environmentally sensitive people in general (Baliatsas et al., 2014). According to some evidence, noise exposure at night is associated with twice as many complaints compared to the rest of the day (Hume et al., 2002), while at higher road-traffic noise levels, sleep disturbances can be associated with noise sensitivity (Lercher, 1995; Miedema and Vos, 2003). A second reason is that night-time exposure is, to some extent, more difficult to avoid compared to daytime exposure, since a part of the population can spend time outdoors for a large part of the day (e.g social activities, work). Finally, in our dataset, night-time and daytime $\left(\mathrm{L}_{\mathrm{den}}\right)$ noise levels were strongly correlated (Spearman rho=0.99).

Information was also obtained on various demographic, residential and lifestyle characteristics, as well as clinical characteristics such as GP-registered physical and psychological morbidity based on ICPC (Lamberts and Wood, 1987). Regarding morbidity, the following conditions were considered: Asthma, acute myocardial infarction, chronic obstructive pulmonary disease (COPD), diabetes, irritable bowel syndrome (IBS), hypertension (uncomplicated), rheumatoid arthritis, vertiginous syndrome, migraine, cancer (malignant neoplasm), anxiety disorder and depressive disorder.

\subsection{Analysis}

Cramer's V, unpaired samples t-test and the chi-squared test were conducted for the descriptive analyses; the latter was also used to assess the prevalence of other sensitivities within the HNS group. To examine potential differences between the HNS group and controls in terms of NSS, symptom perceptions, health status and illness behavior, linear (for the continuous outcomes) and logistic (for the dichotomous outcomes) regression analyses were performed to adjust for night-time road traffic noise exposure, age, gender, education, ethnic background, degree of urbanization, physical morbidity (chronic conditions such COPD and hypertension as indicated in Table 1), psychological morbidity (anxiety and depression) and alcohol/substance abuse. The examined continuous scores did not exceed the acceptable values for skewness and kurtosis (Cameron, 2004). Correlation between covariates and the Variance Inflation Factor (VIF) did not indicate risk for multicollinearity. Statistical analyses were carried out using STATA version 13.0 (StataCorp LP, College Station, TX, USA) and IBM SPSS Statistics (SPSS Inc version 20, Chicago IL, USA). 


\section{Results}

\subsection{Non-response and descriptive analysis}

Detailed results from non-response analysis were described elsewhere (Baliatsas et al., 2014, 2015). In short, participants were younger, higher educated and reported better general health.

There was no significant difference regarding gender distribution. After excluding cases $(n=127)$ with incomplete data related to the case definition of noise sensitivity, 5806 respondents were available for analysis; $n=722(12.5 \%)$ comprised the HNS group. Sample characteristics are presented in Table 1 .

\subsection{Co-occurrence with environmental sensitivities}

Figure 1 shows the co-occurrence between HNS and several other environmental sensitivities. Half of the noise-sensitive individuals reported to be sensitive to warm/cold environment and smells as well. Particularly high co-occurrence was observed also with sensitivity to colors, light, temperature changes, scented detergents and chemical substances, ranging between $33 \%$ and $44 \%$. The prevalence of at least one other environmental sensitivity in the HNS group was $88 \%$.

After controlling for covariates (noise excluded), HNS individuals had a higher probability (OR, 95\% CI) of being highly sensitive to other environmental stressors, compared with the LNS (reference) group: Warm/Cold environment, 3.51 (2.94-4.2); smells, 3.76 (3.15-4.5); color, 2.09 (1.75-2.5); light, 5.35 (4.44-6.46); temperature changes, 4.1 (3.37-4.95); scented detergents, 4.33 (3.55-5.29); chemical substances, 6.48 (5.21-8.04); materials, 3.6 (2.78-4.67); IEI-EMF, 3.36 (2.364.79); at least one of the aforementioned sensitivities, 5.6 (4.38-7.16), ( $\mathrm{p}<0.001$ for all comparisons).

\subsection{Symptom prevalence and duration}

The HNS group had a higher prevalence of all self-reported NSS experienced in the past month and also a higher prevalence of chronic symptoms ( $\geq 4$ months) compared to controls (Tables 2 and 3). Adjusted prevalence was significantly higher as well, for the majority of the symptoms in the HNS group. Differences in psychological/neurovegetative, cardiovascular and ear symptoms were particularly pronounced. The prevalence of GP-registered NSS among noise-sensitive people was $45.2 \%$ (versus $36 \%$ in the LNS group).

\subsection{Symptom scores, perceptions, health status and illness behavior}

People with HNS reported a mean of 8.3 (SD 5.4) self-reported symptoms while the LNS group 5.8 (SD 4.5). Furthermore, the prevalence of GP-registered painkillers, benzodiazepines and antidepressants in the HNS group was $21.9 \%, 18.3 \%$ and $14.7 \%$ respectively, versus $20.4 \%, 9 \%$ and $6.9 \%$ respectively in the LNS group. Scores on number and duration of self-reported NSS as well as the prevalence of GP-registered NSS and prescribed medication (except for painkillers) were significantly higher among participants with HNS (Table 4). Compared to the rest of the sample, they also reported worse sleep quality and physical functioning, higher levels of mental distress, increased 
healthcare utilization and more negative symptom perceptions. Results remained significant after

\section{Discussion}

The primary aim of this study was to give insight into the symptomatic profile and health characteristics of people with self-reported noise sensitivity. Compared to the rest of the sample, the prevalence of self-reported and GP-registered NSS and registered prescriptions for antidepressants and benzodiazepines was considerably higher in the HNS group. Noise-sensitive individuals also reported more chronic NSS, increased psychological distress, decreased sleep quality and general health, more negative symptom perceptions and more healthcare contacts. Modeled night-time noise levels from road-traffic slightly exceeded the thresholds proposed in the WHO guidelines, (WHO, 2009). However, night-time noise exposure did not differ between the two groups, corroborating previous findings regarding independency of noise sensitivity from noise levels (Miedema and Vos, 2003; van Kamp et al., 2004), while most of the examined between-group differences remained significant after adjustment for noise levels as well as for GP-registered physical and psychological morbidity. Cooccurrence with other environmental sensitivities was generally moderate to high, reaching up to 50\%. Results are in line with the limited existing evidence for noise-sensitive groups (Fyhri and Klaeboe, 2009; Palmquist et al., 2014; Stansfeld and Shipley, 2015) and findings from epidemiological studies on people with diverse environmental intolerances and vulnerable population groups such as disaster survivors (van den Berg et al., 2005; Baliatsas et al., 2014).

To our knowledge this is the most extensive epidemiological study to date on symptoms and related characteristics of noise-sensitive individuals, based on a large sample and combining selfreported assessment of number and duration of NSS and real-life general practice data. Furthermore we took into account noise estimates and adjusted for clinically defined morbidity, which makes unlikely that high symptom report in the HNS group and the consistently significant between-group differences are the result of a known disorder.

Some limitations must be acknowledged: First, since participants generally reported a higher score on perceived health compared to the non-respondents, the prevalence of symptoms might be underestimated in the sample, to some degree. Second, we used a simple, self-reported case definition for HNS, which, however, was independent of symptom attribution, targeting to an objective exploration of symptom profiles and characteristics. Simplified definitions were also used for the identification of other environmental sensitivities in the sample, such as sensitivity to chemicals; this could, to some extent, limit comparability with studies that used standardized questionnaires of multiple chemical sensitivity (Miller and Prihoda, 1999). Finally, it is unknown whether exposure to other pollutants may explain increased symptomatology in the HNS group and the extensive overlap with other sensitivities. A previously published epidemiological risk assessment demonstrated no 
convincing evidence for an association between EMF exposure and symptoms in this sample (Baliatsas et al., 2015).

Future research efforts need to replicate these findings and further examine clinical characteristics of people with HNS, test possible psychophysiological mechanisms of symptom report (White et al., 2010) and determine the overlap with the broader spectrum of environmental sensitivities. Establishment of a uniform, broadly accepted case definition for such sensitivities would enhance between-study comparability and lay the ground for therapeutic interventions for the severe cases. Longitudinal studies could determine whether noise sensitivity precedes or follows symptomatology and morbidity (Stansfeld, 1992). The combination of validated instruments and primary care data would be a valuable asset.

Considering previous research in the Netherlands showing that noise sensitivity is strongly associated with a need for quiet (Booi and van den Berg, 2010; van Kempen et al, 2011), noisesensitive individuals could profit from strategies to reduce noise in the urban environment, such as easy access to quiet spaces (Battaner-Moro et al., 2010).

\section{Conclusions}

The view that noise sensitivity might at least partly overlap with the broader concept of self-declared environmental sensitivity is corroborated by the current findings, which add to existing evidence that environmentally sensitive groups share common characteristics such as: 1) High co-occurrence rate with other sensitivities 2) Decreased health status, illness behavior and more negative symptom perceptions, 3) Higher prevalence and duration of all symptoms in different organ systems, even after adjusting for physical exposure to environmental stressors and morbidity and 4) Prominence of neurovegetative and psychological symptoms.

\section{Acknowledgements}

Data were collected within the framework of the project EMPHASIS "Non-specific physical symptoms in relation to actual and perceived exposure to EMF and the underlying mechanisms", funded by The Netherlands Organization for Health Research and Development (ZonMw) (project number: 85100002). The study sponsor had no involvement in study design and data collection and interpretation. We gratefully acknowledge the cooperation of participants and GPs. In addition, we would like to thank Dr. Gert Kelfkens for his contribution on the GIS procedures, Petra ten Veen and Elsbeth de Leeuw-Stravers regarding their help on management of the EMR data and our colleagues at NIVEL for their feedback on the paper. 


\section{References}

Baliatsas, C., van Kamp, I., Hooiveld, M., Yzermans, J., Lebret, E., 2014. Comparing nonspecific physical symptoms in environmentally sensitive patients: prevalence, duration, functional status and illness behavior. J. Psychosom. Res. 76, 405-413.

Baliatsas, C., Bolte, J., Yzermans, J., Kelfkens, G., Hooiveld, M., Lebret, E., et al., 2015. Actual and perceived exposure to electromagnetic fields and non-specific physical symptoms: An epidemiological study based on self-reported data and electronic medical records. International journal of hygiene and environmental health 218, 331-344.

Barsky, A.J., Borus, J.F., 1999. Functional somatic syndromes. Ann. Intern. Med. 130, 910-21.

Battaner-Moro, J., Barlow, C., Wright, P., 2010. A quiet area accessibility metric for the Southampton urban agglomeration. In: Proceedings of the 39th International Congress on Noise Control Engineering (Internoise), 1820-1829.

Booi, H., van den Berg, F., 2012. Quiet areas and the need for quietness in Amsterdam. International journal of environmental research and public health 9, 1030-1050.

Broadbent, E., Petrie, K. J., Main, J., Weinman, J., 2006. The brief illness perception questionnaire. Journal of psychosomatic research, 60, 631-637.

Cameron, A., 2004. Kurtosis. In: Lewis-Beck, M., Bryman, A., Liao, T. (Eds.), Encyclopedia of social science research methods.SAGE Publications, Thousand Oaks CA pp. 544-545.

Das-Munshi, J., Rubin, G. J., Wessely, S., 2006. Multiple chemical sensitivities: A systematic review of provocation studies. Journal of Allergy and Clinical Immunology 118, 1257-1264.

European Commission. 2002. Directive 2002/49/EC of the European Parliament and of the Council of 25 June 2002 relating to the assessment and management of environmental noise. Official Journal of the European Communities L189 of 18.7.2002, 12-25.

Fyhri, A., Klaeboe, R., 2009. Road traffic noise, sensitivity, annoyance and self-reported health - a structural equation model exercise. Environ. Int. 35, 91-97.

Heinonen-Guzejev, M., Vuorinen, H. S., Mussalo-Rauhamaa, H., Heikkilä, K., Koskenvuo, M., Kaprio, J., 2004. Somatic and psychological characteristics of noise-sensitive adults in Finland. Archives of Environmental Health: An International Journal 59, 410-417.

Heinonen-Guzejev, M., Vuorinen, H. S., Mussalo-Rauhamaa, H., Heikkilä, K., Koskenvuo, M., Kaprio, J., 2007. The association of noise sensitivity with coronary heart and cardiovascular mortality among Finnish adults. Science of the total environment, 372, 406-412.

Heinonen-Guzejev, M., Koskenvuo, M., Silventoinen, K., Mussalo-Rauhamaa, H., Vuorinen, H. S., Heikkilä, K., et al., 2013. Noise sensitivity and disability retirement: A longitudinal twin study. Journal of Occupational and Environmental Medicine 55, 365-370.

Henningsen, P., Fink, P., Hausteiner-Wiehle, C., Rief, W., 2011. Terminology, classification and concepts. In: Creed, F., Henningsen, P., Fink, P. (Eds.), Medically Unexplained Symptoms, Somatization and Bodily Distress: Developing Better Clinical Services. Cambridge University Press, pp. 43-68.

Hoeymans, N., Garssen, A. A., Westert, G. P., Verhaak, P. F., 2004. Measuring mental health of the Dutch population: a comparison of the GHQ-12 and the MHI-5. Health Qual Life Outcomes 2, 23.

Hume, K., Terranova, D., Thomas, C., 2002. Complaints and annoyance caused by aircraft operations: Temporal patterns and individual bias. Noise and Health 4, 45.

Job, R.F.S., 1999. Noise sensitivity as a factor influencing human reaction to noise. Noise Health $1,57-68$

Kishikawa, H., Matsui, T., Uchiyama, I., Miyakawa, M., Hiramatsu, K., Stansfeld, S. A., 2009. Noise sensitivity and subjective health: Questionnaire study conducted along trunk roads in Kusatsu, Japan. Noise and Health 11, 111.

Kroenke, L., Price, R.K., 1993. Symptoms in the community. Prevalence, classification, and psychiatric comorbidity. Arch. Intern. Med. 153, 2474-80.

Lamberts, H., Wood, M., 1987. International Classification of Primary Care. Oxford University Press, Oxford.

Lercher, P., 1995. Distinguishing effects modifiers of psychological morbidity associated with traffic noise exposure. Epidemiology S28, P085. 
Miedema, H. M., Vos, H., 2003. Noise sensitivity and reactions to noise and other environmental conditions. The Journal of the Acoustical Society of America 113, 1492-1504.

Miller, C. S., Prihoda, T. J., 1999. The Environmental Exposure and Sensitivity Inventory (ESSI): a standardized approach for measuring chemical intolerances for research and clinical applications. Toxicology and Industrial Health, 15, 370-385.

Nordin, S., Ljungberg, J. K., Claeson, A. S., Neely, G., 2013. Stress and odor sensitivity in persons with noise sensitivity. Noise and Health $15,173$.

Palmquist, E., Claeson, A. S., Neely, G., Stenberg, B., Nordin, S., 2014. Overlap in prevalence between various types of environmental intolerance. International journal of hygiene and environmental health 217, 427-434.

Schreurs, E., Jabben, J., Bergmans, B., Koeman, T., 2010. Background noise: An increasing environmental problem? Acta Acust. United Acust. 96, 1125-33.

Schreurs E., Jabben, J., Verheijen ,E.N., 2011. STAMINA Model Description. Standard Model Instrumentation for Noise Assessments. Bilthoven: RIVM report. Available: http://www.rivm.nl/dsresource?objectid=rivmp:184461\&type=org\&disposition=inline\&ns_nc $=1$ (accessed 30.09.15).

Stansfeld, S. A., Clark, C. R., Jenkins, L. M., Tarnopolsky, A., 1985. Sensitivity to noise in a community sample: I. Measurement of psychiatric disorder and personality. Psychological Medicine, 15, 243-254.

Stansfeld, S. A., 1992. Noise, noise sensitivity and psychiatric disorder: epidemiological and psychophysiological studies. Psychological medicine. Monograph supplement 22, 1-44.

Stansfeld, S.A., Sharp, D., Gallacher, J., Babisch W., 1993. Road traffic noise, noise sensitivity and psychological disorder. Psychol. Med. 23, 977-985.

Stansfeld, S. A., Shipley, M., 2015. Noise sensitivity and future risk of illness and mortality. Science of the Total Environment 520, 114-119.

Staudenmayer, H., Binkley, K. E., Leznoff, A.,Phillips, S., 2003. Idiopathic environmental intolerance. Toxicological reviews 22, 235-246.

van den Berg, B., Grievink, L., Stellato, R.K., Yzermans, C.J., Lebret, E., 2005. Symptoms and related functioning in a traumatized community. Arch. Intern. Med. 165, 2402-2407.

van der Lei, J., Duisterhout, J.S., Westerhof, H.P., van der Does, E., Cromme, P.V.M., Boon, W.M., et al., 1993. The introduction of computer-based patient records in the Netherlands. Ann Intern Med 19:1036-1041.

Van der Zee, K., Sanderman, R. 1993. RAND-36. Groningen: Northern Centre for Health Care Research, University of Groningen, the Netherlands, 28.

van Kamp, I., Job, R. S., Hatfield, J., Haines, M., Stellato, R. K., Stansfeld, S. A., 2004. The role of noise sensitivity in the noise-response relation: a comparison of three international airport studies. The Journal of the Acoustical Society of America 116, 3471-3479.

van Kamp, I., van Kempen, E., Baliatsas, C., Houthuijs, D., 2013. Mental health as context rather than health outcome of noise: Competing hypotheses regarding the role of sensitivity, perceived soundscapes and restoration. In: Proceedings of the International Congress on Noise Control Engineering (Internoise) 247, 3804-3811.

van Kamp, I., Davies, H., 2013. Noise and health in vulnerable groups: a review. Noise and Health 15, 153.

Van Kempen, E., van Kamp, I., Kruize, H., 2011. The need for and access to quiet areas in relation to annoyance, health and sensitivity. In: International Commission on Biological Effects of Noise. Proceedings of the 10th international congress on noise as a public health problem. London: Imperial College, 440-447.

Visser, P., Hofman, W.F., Kumar, A., Cluydts, R., de Diana, I.P.F., Marchant, P., et al., 1978. Sleep and mood: measuring the sleep quality. In: Priest, R.G., Pletscher, A., Ward, J. (Eds.), Proc. of the North Eur. Symp. on Sleep Research. MTP Press Limited, Basel, Lancaster, pp. 135-145.

Yzermans, J., Baliatsas, C., van Dulmen, S., Van Kamp, I., 2016. Assessing non-specific symptoms in epidemiological studies: development and validation of the symptoms and perceptions (SaP) questionnaire. International Journal of Hygiene and Environmental Health 219, 53-65. 
White, K., Hofman, W. F., van Kamp, I., 2010. Noise sensitivity in relation to baseline arousal, physiological response and psychological features to noise exposure during task performance. In: Proceedings of the International Congress on Noise Control Engineering (Internoise), 1-7

WONCA Classification Committee, 1995. An international glossary for general/family practice. Fam. Pract. 12, 341-369.

World Health Organization (WHO)., 2003. Guidelines for ATC classification and DDD assignment. Oslo: WHO Collaborating Centre for Drug Statistics Methodology.

World Health Organization (WHO)., 2009. Night noise guidelines for Europe. Copenhagen: Regional Office for Europe.

Available: http://www.euro.who.int/__data/assets/pdf_file/0017/43316/E92845.pdf (accessed 10.11.15) 


\section{Tables}

\section{Table 1}

Demographic, noise exposure residential and clinical characteristics and lifestyle indicators in the investigated groups (valid cases)

\section{Demographic characteristics}

Mean age (SD)

Female gender $(\%)$

Education $^{\mathrm{a}}(\%)$

Lower

Middle

Higher

Foreign ethnic background ${ }^{\mathrm{b}}(\%)$

\begin{tabular}{cc}
$\begin{array}{c}\text { LNS group } \\
(\mathrm{n}=5084)\end{array}$ & $\begin{array}{c}\text { HNS group } \\
(\mathrm{n}=722)\end{array}$ \\
\hline
\end{tabular}

Modeled Environmental noise exposure

Mean night-time road traffic noise exposure in $\mathrm{dB}$ (SD)

$\begin{array}{ll}51.3(17.2) & 56.0(16.5)^{*} \\ 56.9 & 67.6^{*} \\ & \\ 23.3 & 24.0 \\ 44.8 & 43.4 \\ 32.0 & 32.6 \\ 11.7 & 18.3^{*}\end{array}$

Residential Characteristics

Degree of urbanization (\%)

Extremely urbanized

$44.6(5.83) \quad 44.7(5.61)$

Strongly urbanized

Moderately urbanized

22.6

24.4

24.9

Hardly urbanized

16.0

19.2

Not urbanized

Physical morbidity (registered) (\%)

Asthma

$3.6 \quad 4.6$

Acute myocardial infarction

$0.9 \quad 1.2$

Chronic obstructive pulmonary disease (COPD)

$2.7 \quad 3.9$

Diabetes

$\begin{array}{ll}5.8 & 7.6\end{array}$

Irritable bowel syndrome (IBS)

1.0

Hypertension (uncomplicated)

12.1

1.0

Rheumatoid arthritis

$15.2^{*}$

Vertiginous syndrome

Migraine

Psychological morbidity (registered) (\%)

Anxiety disorder

1.12 .8 *

Depressive disorder

Lifestyle indicators

Mean BMI (Body mass index) (SD)

Note: Significance level set at $\mathrm{p}<.05$.

* Significant difference between LNS \& HNS group.

${ }^{\text {a }}$ Lower: No education or primary school or lower secondary education ; Middle: Intermediate vocational or intermediate general secondary or higher general secondary education; Higher: Higher vocational or university education.

b Not born in the Netherlands or at least one of the parents was born abroad Abbreviations: $\mathrm{dB}$, decibel scale. 
Table 2

Prevalence of self-reported NSS (experienced in the past month) in people with HNS and the rest of the sample and between-group differences ${ }^{\text {a }}$

\begin{tabular}{|c|c|c|c|}
\hline elf-reported NSS & $\mathrm{LNS}^{\mathrm{b}}$ & HNS & OR $(95 \% \mathrm{CI})$ \\
\hline Fatigue/tiredness & 52.3 & 67.7 & $1.97(1.63-2.38)$ \\
\hline Abdominal/stomach pain & 23.4 & 33.2 & $1.54(1.27-1.86)^{* * *}$ \\
\hline Nausea & 11.2 & 18.8 & $1.75(1.38-2.22)^{* * * *}$ \\
\hline Diarrhea or constipation & 20.6 & 28.4 & $1.44(1.18-1.75)^{* * *}$ \\
\hline Eye irritation & 18.6 & 23.8 & $1.19(.97-1.46)$ \\
\hline Ear symptoms & 12.3 & 24.8 & $2.17(1.76-2.67)^{* * *}$ \\
\hline Heart palpitations/awareness & 12.4 & 24.4 & $1.96(1.58-2.43)^{* * * *}$ \\
\hline Neck or shoulder symptoms & 37.8 & 46.0 & $1.22(1.02-1.45)^{*}$ \\
\hline Back problems & 36.0 & 39.9 & $1.07(.9-1.28)$ \\
\hline Pain or pressure in chest & 8.5 & 17.9 & $2.04(1.59-2.61)^{* * *}$ \\
\hline Arm/elbow/hand/wrist symptoms & 24.2 & 31.3 & $1.15(.95-1.4)$ \\
\hline Leg/hip/knee/foot symptoms & 32.1 & 42.6 & $1.27(1.06-1.52)^{* *}$ \\
\hline Pain in muscles & 31.2 & 34.0 & $1.08(.9-1.3)$ \\
\hline Headache & 37.3 & 45.2 & $1.46(1.22-1.76)^{* * *}$ \\
\hline Tingling of fingers, feet or toes & 15.7 & 26.7 & $1.73(1.41-2.12)^{* * *}$ \\
\hline Dizziness or feeling light-headed & 19.9 & 33.7 & $1.80(1.49-2.18)^{* * *}$ \\
\hline Feeling anxious/nervous/tense & 21.9 & 41.3 & $2.31(1.92-2.79)^{* * *}$ \\
\hline Feeling down/depressed & 14.4 & 31.4 & $2.41(1.96-2.97)^{* * *}$ \\
\hline Acute (intense) stress or crisis & 11.0 & 19.9 & $1.82(1.43-2.31)^{* * *}$ \\
\hline Feeling irritable/angry & 23.5 & 39.8 & $2.18(1.81-2.62)^{* * * *}$ \\
\hline Memory or concentration problems & 19.8 & 35.2 & $1.96(1.62-2.36)^{* * *}$ \\
\hline Sleep problems & 25.5 & 44.6 & $1.94(1.63-2.32)^{* * *}$ \\
\hline Shortness of breath or wheezing & 8.3 & 13.1 & $1.37(1.04-1.82){ }^{*}$ \\
\hline Cough & 22.6 & 22.8 & $0.95(0.77-1.17)$ \\
\hline Nasal symptoms & 25.2 & 29.9 & $1.21(1.01-1.47)^{*}$ \\
\hline Skin symptoms & 22.6 & 31.5 & $1.47(1.22-1.77)^{* * *}$ \\
\hline Weight change & 11.5 & 17.9 & $1.44(1.13-1.83)^{* *}$ \\
\hline
\end{tabular}

${ }^{a}$ Between-group differences were adjusted for night-time road traffic noise exposure, age, gender, education, ethnic background, degree of urbanization, physical morbidity, psychological morbidity, alcohol/substance abuse.

${ }^{b}$ Reference group. Note: ${ }^{*} \mathrm{p}<.05 ;{ }^{* *} \mathrm{p}<.01 ;{ }^{* * *} \mathrm{p}<.001$.

Abbreviations: OR, Odds ratio; CI, Confidence interval. 


\section{Table 3}

Prevalence of self-reported NSS with duration of $\geq 4$ months in people with HNS and the rest of the sample and between-group differences ${ }^{\text {a }}$

\begin{tabular}{|c|c|c|c|}
\hline & $\mathrm{LNS}^{\mathrm{b}}$ & HNS & OR $(95 \% \mathrm{CI})$ \\
\hline Fatigue/tiredness & 23.5 & 39.4 & $1.9(1.58-2.28)^{* * * * *}$ \\
\hline Abdominal/stomach pain & 9.1 & 16.0 & $1.7(1.33-2.19)^{* *}$ \\
\hline Nausea & 2.3 & 6.1 & $2.18(1.44-3.29)^{* * *}$ \\
\hline Diarrhea or constipation & 6.4 & 12.0 & $1.85(1.39-2.45)^{* * * *}$ \\
\hline Eye symptoms & 6.6 & 12.4 & $1.67(1.26-2.22)^{* * *}$ \\
\hline Ear symptoms & 6.1 & 14.1 & $2.27(1.73-2.98)^{* * *}$ \\
\hline Heart palpitations/awareness & 5.5 & 12.4 & $2.18(1.64-2.9)^{* * * *}$ \\
\hline Neck or shoulder symptoms & 19.5 & 29.7 & $1.5(1.23-1.82)^{* * * *}$ \\
\hline Back pain & 19.0 & 25.3 & $1.25(1.02-1.53)^{*}$ \\
\hline Pain/pressure in chest and heart region & 3.3 & 9.3 & $2.54(1.8-3.56)^{* * * *}$ \\
\hline Arm/elbow/hand/wrist symptoms & 13.8 & 22.9 & $1.49(1.2-1.85)^{* * * *}$ \\
\hline Leg/hip/knee/foot symptoms & 19.8 & 29.1 & $1.33(1.08-1.63)^{* *}$ \\
\hline Pain in muscles & 8.9 & 15.3 & $1.5(1.16-1.94)^{* *}$ \\
\hline Headache & 10.3 & 21.1 & $2.18(1.74-2.75)^{* * *}$ \\
\hline Tingling of fingers, feet or toes & 8.6 & 15.5 & $1.7(1.32-2.19)^{* * * *}$ \\
\hline Dizziness or feeling light-headed & 7.4 & 17.4 & $2.33(1.81-3.01)^{* * *}$ \\
\hline Feeling anxious/nervous/tense & 9.8 & 25.6 & $2.72(2.17-3.41)^{* * *}$ \\
\hline Feeling down/depressed & 6.8 & 18.8 & $2.72(2.1-3.53)^{* * * *}$ \\
\hline Acute (intense) stress or crisis & 4.3 & 11.0 & $2.53(1.84-3.5)^{* * * *}$ \\
\hline Feeling irritable/angry & 8.2 & 20.1 & $2.55(2.0-3.26)^{* * *}$ \\
\hline Memory or concentration problems & 11.6 & 23.7 & $2.02(1.61-2.52)^{* * *}$ \\
\hline Sleep problems & 14.6 & 29.8 & $2.01(1.63-2.46)^{* * *}$ \\
\hline Shortness of breath or wheezing & 4.3 & 7.4 & $1.51(1.06-2.16)^{*}$ \\
\hline Cough & 5.6 & 6.9 & $0.94(0.65-1.36)$ \\
\hline Nasal symptoms & 10.6 & 15.8 & $1.44(1.13-1.85)^{\text {** }}$ \\
\hline Skin symptoms & 12.3 & 19.1 & $1.5(1.19-1.88)^{* * *}$ \\
\hline Weight change & 6.5 & 10.2 & $1.34(0.98-1.81)$ \\
\hline
\end{tabular}

${ }^{a}$ Between-group differences were adjusted for night-time road traffic noise exposure, age, gender, education, ethnic background, degree of urbanization, physical morbidity, psychological morbidity, alcohol/substance abuse.

${ }^{\mathrm{b}}$ Reference group.

Note: ${ }^{*} \mathrm{p}<.05 ;{ }^{* *} \mathrm{p}<.01 ;{ }^{* * *} \mathrm{p}<.001$.

Abbreviations: OR, Odds ratio; CI, Confidence interval. 


\section{Table 4}

Unadjusted and adjusted differences between groups on determinants of health status, illness behavior, symptom perceptions \& symptom score

\begin{tabular}{|c|c|c|}
\hline & \multicolumn{2}{|c|}{ HNS vs. LNS $^{\text {a }}$} \\
\hline & Unadjusted & Adjusted $^{\mathrm{b}}$ \\
\hline Health status \& symptom scores & & \\
\hline $\begin{array}{l}\text { Regression coefficient }(95 \% \text { CI) } \\
\text { General health } \\
\text { Sleep quality } \\
\text { Psychological distress } \\
\text { Number of self-reported NSS } \\
\text { Duration of self-reported NSS }\end{array}$ & $\begin{array}{l}-7.4(-8.86-5.95)^{* * *} \\
1.00(0.78-1.22)^{* * *} \\
1.82(1.4-2.24)^{* * *} \\
2.5(2.13-2.88)^{* * *} \\
8.86(7.67-10.0)^{* * *}\end{array}$ & $\begin{array}{l}-5.52(-6.95-4.09)^{* * *} \\
0.76(0.54-0.98)^{* * *} \\
1.41(0.98-1.84)^{* * *} \\
2.01(1.65-2.38)^{* * *} \\
7.03(5.89-8.18)^{* * *}\end{array}$ \\
\hline $\begin{array}{l}\text { OR }(95 \% \text { CI }) \\
\text { GP-registered NSS } \\
\text { Prescribed painkillers } \\
\text { Prescribed benzodiazepines } \\
\text { Prescribed antidepressants }\end{array}$ & $\begin{array}{l}1.46(1.24-1.71)^{* * *} \\
1.1(0.91-1.32) \\
2.25(1.82-2.79)^{* * *} \\
2.33(1.85-2.95)^{* * *}\end{array}$ & $\begin{array}{l}1.25(1.05-1.49)^{*} \\
0.97(0.78-1.2) \\
1.69(1.32-2.18)^{* * *} \\
1.84(1.37-2.48)^{* * *}\end{array}$ \\
\hline $\begin{array}{l}\text { Symptom perceptions }{ }^{\dagger} \& \text { illness behavior } \\
\text { Regression coefficient }(95 \% \text { CI) } \\
\text { Symptom perceptions }(\mathrm{t})^{\top} \\
\text { Symptom perceptions }(\mathrm{n} . \mathrm{t})^{\neq}\end{array}$ & $\begin{array}{l}3.18(1.61-4.74)^{* * * *} \\
4.54(3.48-5.6)^{* * *}\end{array}$ & $\begin{array}{l}2.6(0.99-4.21)^{* *} \\
3.41(2.35-4.48)^{* * *}\end{array}$ \\
\hline $\begin{array}{l}\text { OR }(95 \% \text { CI }) \\
\text { Consulting a GP } \\
\text { Consulting a psychologist } \\
\text { Consulting an alternative therapist } \\
\text { Unprescribed medication }\end{array}$ & $\begin{array}{l}1.81(1.47-2.22)^{* * *} \\
2.17(1.76-2.67)^{* * *} \\
1.77(1.39-2.25)^{* * *} \\
1.29(1.09-1.51)^{* *}\end{array}$ & $\begin{array}{l}1.51(1.21-1.89)^{* * *} \\
2.09(1.65-2.65)^{* * *} \\
1.72(1.32-2.23)^{* * *} \\
1.23(1.03-1.47)^{*}\end{array}$ \\
\hline
\end{tabular}

${ }^{\mathrm{a}}$ Reference group.

Note: ${ }^{*} \mathrm{p}<.05 ;{ }^{* *} \mathrm{p}<.01 ;{ }^{* * *} \mathrm{p}<.001$.

${ }^{\mathrm{b}}$ Between-group differences were adjusted for night-time road traffic noise exposure, age, gender education, ethnic background, degree of urbanization, physical morbidity, psychological morbidity, alcohol/substance abuse.

${ }^{\dagger}$ Referring to the most important/severe symptom among the ones reported.

T Participants following treatment for their most important symptom.

₹ Participants not following treatment for their most important symptom.

Abbreviations: OR, Odds ratio; CI, Confidence interval. 


\section{Figure 1}

Prevalence of other environmental sensitivities within the HNS and LNS group

Abbreviations: IEI-EMF, Idiopathic environmental intolerance attributed to electromagnetic fields. 
